Pacific Journal of Mathematics

ABDETERMINANT INEQUALITY

in David Marcus and H. Mine 


\section{A SUBDETERMINANT INEQUALITY}

\section{MaRvin Marcus ${ }^{1}$ and Henryk Minc ${ }^{2}$}

Let $A$ be an $n$-square positive semi-definite hermitian matrix and let $D_{m}(A)$ denote the maximum of all order $m$ principal subdeterminants of $A$. In this note we prove the inequality

$$
\left(D_{m}(A)\right)^{1 / m} \geqq\left(D_{m+1}(A)\right)^{1 /(m+1)}, \quad m=1, \cdots, n-1,
$$

and discuss in detail the case of equality. This result is closely related to Newton's and Szász's inequalities.

Let $A=\left(a_{i j}\right)$ be an $n$-square positive semi-definite hermitian matrix with eigenvalues $\lambda_{1} \geqq \cdots \geqq \lambda_{n} \geqq 0$. We introduce some notation. For $1 \leqq m \leqq n$ let $Q_{m, n}$ denote the set of all $\left(\begin{array}{c}n \\ m\end{array}\right)$ sequences $\omega=\left(\omega_{1}, \cdots, \omega_{m}\right)$, $1 \leqq \omega_{1}<\omega_{2}<\cdots<\omega_{m} \leqq n$. Let $A[\omega \mid \omega]$ denote the $m$-square submatrix of $A$ whose $(i, j)$ entry is $a_{\omega_{i} \omega_{j}}, i, j=1, \cdots, m$.

THEOREM. If $A$ is a positive semi-definite hermitian matrix then

$$
\begin{aligned}
\max _{\alpha \in Q_{m}} & (\operatorname{det}(A[\alpha \mid \alpha]))^{1 / m} \\
& \geqq \max _{\omega \in Q_{m+1, n}}(\operatorname{det}(A[\omega \mid \omega]))^{1 / m+1}, \quad m=1, \cdots, n-1 .
\end{aligned}
$$

Equality holds for a given $m$ if and only if either $A$ has rank less than $m$ or $A\left[\omega^{0} \mid \omega^{0}\right]$ is a multiple of the identity, where the sequence $\omega^{0} \in Q_{m+1, n}$ is one that satisfies

$$
\operatorname{det}\left(A\left[\omega^{0} \mid \omega^{0}\right]\right)=\max _{\omega \in Q_{m+1}} \operatorname{det} A[\omega \mid \omega] .
$$

There are two classical results that are closely related to the inequalities (1). These are Szász's inequalities and the Newton inequalities. Szász proved that [1, p. 119]

$$
\begin{aligned}
& \left(\prod_{\alpha \in Q_{m} n}(\operatorname{det}(A[\alpha \mid \alpha]))^{\left.1 /\left(\begin{array}{l}
n \\
m
\end{array}\right)\right)^{1 / m}}\right. \\
& \quad \geqq\left(\prod_{\omega \in Q_{m+1, n}}(\operatorname{det}(A[\omega \mid \omega]))^{\left.1 /\left(\begin{array}{c}
n \\
m+1
\end{array}\right)\right)^{1 /(m+1)}} .\right.
\end{aligned}
$$

Newton's inequalities $\left[1\right.$, p. 106] state that if $E_{m}(A)$ is the $m$ th elementary symmetric function of the nonnegative numbers $\lambda_{1}, \cdots, \lambda_{n}$ then

Received August 27, 1964.

1 The research of this author was supported by N. S. F. Grant G. P. 1085.

2 The research of this author was supported by U.S. Air Force Grant No. AFAFOSR-432-63. 


$$
\left(E_{m}(A) /\left(\begin{array}{c}
n \\
m
\end{array}\right)\right)^{1 / m} \geqq\left(E_{m+1}(A) /\left(\begin{array}{c}
n \\
m+1
\end{array}\right)\right)^{1 /(m+1)} \cdot
$$

However,

$$
E_{m}(A)=\sum_{\alpha \in \mathbb{Q}_{m}, n} \operatorname{det}(A[\alpha \mid \alpha])
$$

and hence (4) can be written

$$
\begin{aligned}
& \left(\sum_{\omega \in Q_{m}, n} \operatorname{det}(A[\alpha \mid \alpha]) /\left(\begin{array}{c}
n \\
m
\end{array}\right)\right)^{1 / m} \\
& \quad \geqq\left(\sum_{\omega \in Q_{m+1} n} \operatorname{det}(A[\omega \mid \omega]) /\left(\begin{array}{c}
n \\
m+1
\end{array}\right)\right)^{1 /(m+1)} .
\end{aligned}
$$

Notice that (3) compares the geometric mean of the principal subdeterminants of order $m$ with the geometric mean of the principal subdeterminants of order $m+1$. Also (6) makes the same kind of comparison for the arithmetic means of these quantities. The result (1) compares the maxima of the two sets of subdeterminants.

To prove the theorem we state and prove a preliminary lemma.

Lemma. If $A$ is a positive semi-definite n-square hermitian matrix then

$$
\max _{\alpha \in Q_{m n}} \operatorname{det}(A[\alpha \mid \alpha]) \geqq(\operatorname{det}(A))^{m / n}, \quad 1 \leqq m \leqq n .
$$

Equality holds if and only if either the rank of $A$ is less than $m$ or $A$ is a multiple of the identity matrix.

Proof. We use some properties of the compound matrix of $A$, denoted by $C_{m}(A)$. The essential facts concerning $C_{m}(A)$ are [1, pp. 17, 24, 70]:

(i) $\operatorname{det}\left(C_{m}(A)\right)=(\operatorname{det}(A))^{\left(\begin{array}{c}n-1 \\ m-1\end{array}\right)}$ (Sylvester-Franke theorem);

(ii) if $A$ is positive semi-definite hermitian, so is $C_{m}(A)$;

(iii) the characteristic roots of $C_{m}(A)$ are the $\left(\begin{array}{c}n \\ m\end{array}\right)$ products

$$
\prod_{i=1}^{m} \lambda_{\omega_{i}}, \quad \omega \in Q_{m, n} .
$$

We want to prove that

$$
\max _{\alpha \in Q_{m, n}} \operatorname{det}(A[\alpha \mid \alpha]) \geqq(\operatorname{det}(A))^{m / n} .
$$

If we apply the Hadamard determinant theorem [1, p. 114] to $C_{m}(A)$ then we conclude from (i)

$$
\prod_{\alpha \in Q_{m, n}} \operatorname{det}(A[\alpha \mid \alpha]) \geqq \operatorname{det}\left(C_{m}(A)\right)=(\operatorname{det}(A))^{\left(\begin{array}{l}
n-1 \\
m-1
\end{array}\right)} .
$$


If for every $\alpha \in Q_{m, n}$, $\operatorname{det}(A[\alpha \mid \alpha])$ were strictly less than $(\operatorname{det}(A))^{m / n}$ then from (9) we would conclude that

$$
(\operatorname{det}(A))^{\left(\begin{array}{c}
n-1 \\
m-1
\end{array}\right)}<\left((\operatorname{det}(A))^{m / n}\right)^{\left(\begin{array}{l}
n \\
m
\end{array}\right)}=(\operatorname{det}(A))^{\left(\begin{array}{c}
n-1 \\
m-1
\end{array}\right)},
$$

a contradiction. Thus (8) holds. If (8) were equality suppose first that not all $\operatorname{det}(A[\alpha \mid \alpha]), \alpha \in Q_{m, n}$ are equal. Then from (9) we would obtain the same contradiction (10). Thus for equality to hold in (8)

$$
\operatorname{det}(A[\alpha \mid \alpha])=(\operatorname{det}(A))^{m / n}
$$

for all $\alpha \in Q_{m, n}$. This means that all the main diagonal elements of $C_{m}(A)$ are equal. If this common value is 0 then $A$ has rank at most $m-1$. If the common value is nonzero then (9) is equality throughout and as we know from the case of equality in the Hadamard determinant theorem $C_{m}(A)$ is a multiple of the identity. Thus from (iii) we know that the characteristic roots

$$
\prod_{\imath=1}^{m} \lambda_{\alpha_{i}}, \quad \alpha \in Q_{m, n}, \quad m<n,
$$

are equal. But then it follows that $\lambda_{1}=\cdots=\lambda_{n}$ and hence $A$ is a multiple of the identity, completing the proof of the lemma.

To prove the inequality (1) we apply the lemma to submatrices. Let $\omega^{0}$ be a sequence in $Q_{m+1, n}$ for which

$$
\operatorname{det}\left(A\left[\omega^{0} \mid \omega^{0}\right]\right)=\max _{\omega \in Q_{m+1, n}} \operatorname{det}(A[\omega \mid \omega]) .
$$

For $\alpha \in Q_{m, n}$ and $\alpha$ a subsequence of $\omega^{0}$, i.e., $\alpha \subset \omega^{0}$, we know that $A[\alpha \mid \alpha]$ is an $m$-square submatrix of $A\left[\omega^{0} \mid \omega^{0}\right]$. Hence, by the lemma,

$$
\max _{\alpha \in Q_{m}, \alpha \subset \omega^{0}} \operatorname{det}(A[\alpha \mid \alpha]) \geqq\left(\operatorname{det}\left(A\left[\omega^{0} \mid \omega^{0}\right]\right)\right)^{m /(m+1)} .
$$

Thus a fortiori

$$
\max _{\alpha \in Q_{m} n} \operatorname{det}(A[\alpha \mid \alpha]) \geqq\left(\operatorname{det}\left(A\left[\omega^{0} \mid \omega^{0}\right]\right)\right)^{m /(m+1)} .
$$

Applying (11) we obtain the inequality (1) from (13).

If equality holds in (1) then (12) must be equality as well. Therefore either the rank of $A\left[\omega^{0} \mid \omega^{0}\right]$ is less than $m$ or $A\left[\omega^{0} \mid \omega^{0}\right]$ is a multiple of the $(m+1)$-square identity matrix. If the former is the case then $\operatorname{det}\left(A\left[\omega^{0} \mid \omega^{0}\right]\right)=0$ and hence, since (13) is equality, every $m$ th order principal subdeterminant of $A$ is 0 . Thus the $\operatorname{rank}$ of $A$ is less than $m$. 


\section{REFERENCE}

1. Marvin Marcus and Henryk Minc, A Survey of Matrix Theory and Matrix Inequalities, Allyn and Bacon, Boston, 1964.

University of California, SANTA Barbara 


\section{PACIFIC JOURNAL OF MATHEMATICS}

\section{EDITORS}

\author{
H. Samelson \\ Stanford University \\ Stanford, California \\ R. M. Blumenthal \\ University of Washington \\ Seattle, Washington 98105
}

\author{
J. Dugundu \\ University of Southern California \\ Los Angeles, California 90007 \\ *Richard Arens \\ University of California \\ Los Angeles, California 90024
}

\section{ASSOCIATE EDITORS}
E. F. BeCKENBACH
B. H. NeUMANN
F. WOLF
K. YosidA

\section{SUPPORTING INSTITUTIONS}

\author{
UNIVERSITY OF BRITISH COLUMBIA \\ CALIFORNIA INSTITUTE OF TECHNOLOGY \\ UNIVERSITY OF CALIFORNIA \\ MONTANA STATE UNIVERSITY \\ UNIVERSITY OF NEVADA \\ NEW MEXICO STATE UNIVERSITY \\ OREGON STATE UNIVERSITY \\ UNIVERSITY OF OREGON \\ OSAKA UNIVERSITY \\ UNIVERSITY OF SOUTHERN CALIFORNIA
}

\author{
STANFORD UNIVERSITY \\ UNIVERSITY OF TOKYO \\ UNIVERSITY OF UTAH \\ WASHINGTON STATE UNIVERSITY \\ UNIVERSITY OF WASHINGTON \\ * * * * \\ AMERICAN MATHEMATICAL SOCIETY \\ CALIFORNIA RESEARCH CORPORATION \\ SPACE TECHNOLOGY LABORATORIES \\ NAVAL ORDNANCE TEST STATION
}

Mathematical papers intended for publication in the Pacific Journal of Mathematics should by typewritten (double spaced). The first paragraph or two must be capable of being used separately as a synopsis of the entire paper. It should not contain references to the bibliography. No separate author's resumé is required. Manuscripts may be sent to any one of the four editors. All other communications to the editors should be addressed to the managing editor, Richard Arens, at the University of California, Los Angeles, California 90024.

50 reprints per author of each article are furnished free of charge; additional copies may be obtained at cost in multiples of 50 .

The Pacific Journal of Mathematics is published quarterly, in March, June, September, and December. Effective with Volume 13 the price per volume (4 numbers) is $\$ 18.00$; single issues, $\$ 5.00$. Special price for current issues to individual faculty members of supporting institutions and to individual members of the American Mathematical Society: $\$ 8.00$ per volume; single issues $\$ 2.50$. Back numbers are available.

Subscriptions, orders for back numbers, and changes of address should be sent to Pacific Journal of Mathematics, 103 Highland Boulevard, Berkeley 8, California.

Printed at Kokusai Bunken Insatsusha (International Academic Printing Co., Ltd.), No. 6, 2-chome, Fujimi-cho, Chiyoda-ku, Tokyo, Japan.

PUBLISHED BY PACIFIC JOURNAL OF MATHEMATICS, A NON-PROFIT CORPORATION

The Supporting Institutions listed above contribute to the cost of publication of this Journal, but they are not owners or publishers and have no responsibility for its content or policies.

* Basil Gordon, Acting Managing Editor until February 1, 1966. 


\section{Pacific Journal of Mathematics}

\section{Vol. 15, No. $3 \quad$ November, 1965}

David R. Arterburn and Robert James Whitley, Projections in the space of

bounded linear operators .................................

Robert McCallum Blumenthal, Joram Lindenstrauss and Robert Ralph Phelps,

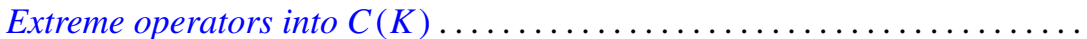

L. Carlitz, A note on multiple exponential sums ................... 757

Joseph A. Cima, A nonnormal Blaschke-quotient .................... 767

Paul Civin and Bertram Yood, Lie and Jordan structures in Banach algebras . . . 775

Luther Elic Claborn, Dedekind domains: Overrings and semi-prime

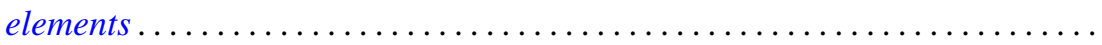

799

Luther Elic Claborn, Note generalizing a result of Samuel's .............. 805

George Bernard Dantzig, E. Eisenberg and Richard Warren Cottle, Symmetric

dual nonlinear programs ................................... 809

Philip J. Davis, Simple quadratures in the complex plane ............... 813

Edward Richard Fadell, On a coincidence theorem of F. B. Fuller ............ 825

Delbert Ray Fulkerson and Oliver Gross, Incidence matrices and interval

graphs ........................................ 835

Larry Charles Grove, Tensor products over $H^{*}$-algebras ..................

Deborah Tepper Haimo, $L^{2}$ expansions in terms of generalized heat polynomials

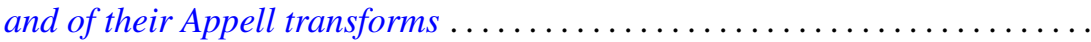

I. Martin (Irving) Isaacs and Donald Steven Passman, A chardcterization of groups in terms of the degrees of their characters ..........

Donald Gordon James, Integral invariants for vectors over local fields........ 905

Fred Krakowski, A remark on the lemma of Gauss ................... 917

Marvin David Marcus and H. Minc, A subdeterminant inequality ........... 921

Kevin Mor McCrimmon, Norms and noncommutative Jordan algebras ........ 925

Donald Earl Myers, Topologies for Laplace transform spaces ............... 957

Olav Njstad, On some classes of nearly open sets .................... 961

Milton Philip Olson, A characterization of conditional probability ........... 971

Barbara Osofsky, A counter-example to a lemma of Skornjakov .............. 985

Sidney Charles Port, Ratio limit theorems for Markov chains ............... 989

George A. Reid, A generalisation of $W^{*}$-algebras ...................... 1019

Robert Wells Ritchie, Classes of recursive functions based on Ackermann's

function ........................................... 1027

Thomas Lawrence Sherman, Properties of solutions of $n$th order linear

differential equations ........................................ 1045

Ernst Snapper, Inflation and deflation for all dimensions . .............. 1061

Kondagunta Sundaresan, On the strict and uniform convexity of certain Banach

spaces............................................. 1083

Frank J. Wagner, Maximal convex filters in a locally convex space .......... 1087

Joseph Albert Wolf, Translation-invariant function algebras on compact 